Opinion

\title{
Climate depends on the water circle of the water, and the circulation depends on the man
}

\section{Opinion}

There was a message that in Russia alone dumps covered 100,000 km.kv. fertile soil. This is the necrosis of the earth. It is known that every blade of grass and every animal consumes water, converts and emits almost all of this moisture. For example, a birch - 200 liters, a cow - 100 liters. You can bring the list more fully.

In addition to landfills, the land is alienated from nature by the fact that it is plowed under agricultural crops, flooded with new and new reservoirs of hydroelectric power stations. Concrete and asphalt new cities and roads. All waters evaporated from such territories, at best, do not change their structure. As they came with rain, they returned back. At worst, they are absorbed and combined with chemical elements, which later, it happens that, with a strong concentration, acid rains fall out. Evaporation from artificial territories is supplemented by evaporation and from the technological processes of industrial and communal industries. In essence, these evaporation is alien to nature. In general, the interaction of plant and animal worlds in a single symbiosis with atmospheric phenomena and created a cycle of water and substances in nature. For millions of years, the volumes and periodicity of precipitation, the places of their precipitation, regularity have stabilized. A consequence of this was the formation of various arid zones: steppes, deserts, forests, tropics - the entire palette of geographic zones, including a comfortable climate inhabited by man, areas.

New volumes of new artificial fumes appeared for nature with the development of human civilization. As it develops, artificial evaporation increases in volume and speed. The quality of evaporation is a little studied area of science, but, in all likelihood, also has some effect on "heavenly cuisine". There cannot be the same evaporation from the drying asphalt and from the plant or from our breath.

Natural disasters of recent years in the world indicate an increasing trend in the development of natural disasters, in climate change.

A propagandized official hypothesis based on carbon dioxide emissions diverts the world community from the true cause of climate change and leads the world to a global catastrophe. If 4 billion tons of carbon dioxide are released into the atmosphere in a year, then only artificial evaporated water is 2200 billion tons.

\author{
Volume 3 Issue 5 - 2018 \\ Khalidullin $\mathrm{O}$ \\ Kazakh National University, Kazakhstan
}

Correspondence: Khalidullin O, Ecology Professor, Kazakh National University, Kazakhstan, Tel 87770550099 , Email7II5215@mail.ru

Received: Septmber 28, 2018 | Published: October II, 2018

"Celestial cuisine" broke, due to changes in its components. The mechanisms of distribution, graphs, and metering of precipitation by zones of the earth's surface disappeared. In some places, destructive floods, in others - drought and fires. Not reaching the poles and mountain zones, water falls into out-of-range areas. Therefore, the level of the oceans is also growing. And this growth is growing in a sufficiently strong progression because the growth of glaciers has stopped.

\section{Is there salvation?}

It is urgent to prove this hypothesis and develop a new concept of saving life on the planet. It should be based on total water saving in production and everyday life by each enterprise, each state, and each person. Do not just make up the rules about the forgotten cranes and reduce the flow of water. It is necessary to radically revise all actions related to water. Water must make a qualitative transition from a working fluid body, a reagent to a living partner. The main purpose of water is its drinking, consumption. All the rest should be reduced to zero.

\section{Acknowledgements}

None.

\section{Conflict of interest}

Author declares that there is no conflict of interest. 